\title{
OBTENÇÃO DE AGREGADO SINTÉTICO POR MEIO DE SINTERIZAÇÃO EM REATOR DE LEITO FIXO
}

\author{
J. E. A. dos SANTOS $^{1}$, L. F. S. PEREIRA ${ }^{1}$, D. S. QUARESMA ${ }^{1}$, E. N. MACÊDO ${ }^{1}$ e J. A. S. \\ SOUZA $^{1}$. \\ ${ }^{1}$ Universidade Federal do Pará, Faculdade de Engenharia Química \\ E-mail para contato: fpereira@ufpa.br
}

\begin{abstract}
RESUMO - Os agregados sintéticos vêm sendo empregados na construção civil como uma medida de reciclagem de resíduos industriais. Este estudo analisa a produção de agregado sintético por sinterização em reator de leito fixo. Confeccionaram-se pelotas com uma mistura de argila, cinza volante (resíduo) e carvão vegetal. O leito foi preenchido com $20 \%$ de pelotas e $80 \%$ de carvão. Utilizando Difração de raios-X e Microscopia eletrônica de varredura constatou-se a presença de mulita. Medindo-se as propriedades cerâmicas do agregado produzido, obteve-se a massa específica aparente de $0,99 \mathrm{~g} / \mathrm{cm} 3$, no $1^{\circ}$ experimento, e $1,03 \mathrm{~g} / \mathrm{cm}^{3}$, no $2^{\circ}$ experimento, caracterizando o material como agregado leve, segundo a ABNT 12655:2015; quanto à porosidade do agregado atingiu-se $10,03 \%$, no $1^{\circ}$ experimento, e $7,90 \%$, no $2^{\circ}$ experimento; e a absorção de água um percentual de $9,91 \%$, no $1^{\circ}$ experimento, e $7,62 \%$, no $2^{\circ}$ experimento. $\mathrm{O}$ processo reduz impactos ambientais, à medida que o material produzido substitui agregados naturais.
\end{abstract}

\section{INTRODUÇÃO}

O uso de novos materiais na indústria da construção civil, sobretudo os materiais provenientes de resíduos industriais, tem sido cada vez mais intenso. Existem pelo menos duas razões básicas que induzem a essa realidade: a primeira deve-se ao grande volume de materiais que a construção civil demanda, e a segunda é devido à vinculação do tema, à valorização e ao uso de resíduos industriais no setor da construção civil e na área de proteção ambiente. É neste cenário que a produção de agregado sintético a partir de resíduos industriais torna-se viável (ROSÁRIO, 2013).

Agregado sintético é o material proveniente da transformação de solo, resíduo sílicoaluminoso ou de outra fonte, previamente processado, em um material inerte com resistência mecânica adequada para determinada finalidade. Tais características são comumente obtidas através da queima deste material em temperaturas elevadas, com temperaturas superiores a $1.100^{\circ} \mathrm{C}(\mathrm{CABRAL}, 2008)$.

A queima do carvão mineral em caldeiras para geração de vapor e produz resíduos durante o processo da combustão, conhecidas como cinzas. As partículas de cinza tendem a apresentar uma forma esférica, o que confere uma boa plasticidade à massa. Uma das 
alternativas de reutilização das cinzas é seu emprego em concretos e argamassas devido sua atividade pozolânica (SIQUEIRA, 2012).

No processo de sinterização é feito uma mistura da matéria prima com uma quantidade definida de combustível. Posteriormente esse material é exposto a temperaturas elevadas, que resultam na expansão devido à formação de gases (GOMES NETO, 1998).

No reator de leito fixo, a fase sólida reage com a fase gasosa, onde ocorrem diversas reações químicas: pirólise, combustão do residual de carbono e reações de estado sólido. Estas reações de transformação são acompanhadas por mudanças bruscas na estrutura física da fase sólida (MARTINS, 2008).

Tendo em vista isso, este trabalho tem por objetivo o estudo da reciclagem de cinza de carvão mineral (cinza volante) e biomassa para produção de agregado sintético por meio de sinterização em reator vertical de leito fixo, aplicando-a em uma mistura de argila e carvão vegetal.

\section{MATERIAIS E MÉTODOS}

A cinza de carvão mineral foi cedida pela indústria HYDRO ALUNORTE e corresponde ao rejeito industrial reaproveitado. A cinza desempenha papel de fundente, ocasionando a diminuição da temperatura no processo de sinterização. A cinza, por apresentar partículas finamente divididas, não necessitou de tratamento prévio e foi utilizada de forma direta nos experimentos.

A argila retirada das margens do rio Guamá foi previamente seca a $105^{\circ} \mathrm{C}$ em estufa com recirculação de ar durante $24 \mathrm{~h}$ e posteriormente desagregada em moinho de bolas por 30 minutos. O carvão vegetal, obtido comercialmente, foi submetido ao mesmo pré-tratamento realizado com a argila e foi, posteriormente, empregada como combustível sólido no processo de sinterização.

O processo de sinterização foi realizado com uma mistura de $20 \%$ do volume do reator de pelotas (constituída a partir das matérias-primas) e $80 \%$ de carvão vegetal em todos os experimentos. Foram realizados dois experimentos para a obtenção do agregado sintético variando-se a velocidade de sucção do ar, sendo utilizado $0,68 \mathrm{~m} \cdot \mathrm{s}^{-1}$ no primeiro experimento e $1,26 \mathrm{~m} \cdot \mathrm{s}^{-1}$ no segundo.

O preparo das pelotas foi realizado a partir de uma mistura de $40 \%$ de cinza, $30 \%$ de argila e 30\% de carvão em peso, a qual foi adicionada ao moinho de bolas durante 60 minutos, posteriormente a mesma foi colocada em um tambor rotativo onde as pelotas eram formadas com adição de $40 \%$ de água em peso, apresentando tamanhos variados. Após essa etapa, as pelotas foram colocadas em estufa à temperatura de $105^{\circ} \mathrm{C}$ durante $24 \mathrm{~h}$ para secagem, seguida de classificação para uma granulometria inferior a $6,35 \mathrm{~mm}$ e maior ou igual a $4 \mathrm{~mm}$.

Para a preparação do carvão que preencheu $80 \%$ do volume do reator, realizou-se um processo de secagem durante 24 horas à $105^{\circ} \mathrm{C}$, britagem e moagem em moinho de discos. Ato contínuo ao processo, o material foi classificado para uma granulometria inferior a $3,36 \mathrm{~mm}$ e maior ou igual a $1,70 \mathrm{~mm}$. 
Após essa etapa os materiais foram homogeneizados manualmente. Preparada a mistura, a mesma foi submetida a secagem por 24 horas à $105^{\circ} \mathrm{C}$ em estufa com recirculação de ar e em seguida sinterizada em um reator vertical de leito fixo.

Para o início do experimento, um maçarico acoplado a um botijão de gás GLP, executa a queima do gás e proporciona uma chama regulável, o qual é utilizado na parte superior do reator para dar ignição à combustão, definida para uma temperatura de $700^{\circ} \mathrm{C}$. Um ventilador é adaptado através de um tubo de aço carbono conectado a parte inferior do reator para succionar o ar, que contém o comburente da reação, promovendo assim o avanço da frente de combustão dentro do reator. A análise do avanço da frente de combustão e das temperaturas no interior do leito é feito através da medição de temperaturas utilizando-se termopares dispostos verticalmente no reator. As velocidades de sucção do ar eram medidas através do termoanemômetro CFM. A aquisição dos dados de temperatura foi registrada no Paperless Recorder, tipo PHL a cada 5 segundos.

Após processo de sinterização obteve-se o agregado sintético apresentando tamanhos variados, conforme pode ser observado na Figura 1.

Figura 1 - Agregados sintéticos produzidos.

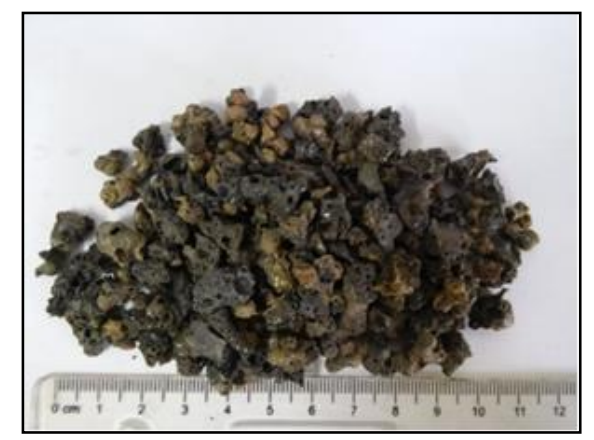

Realizaram-se ensaios para a determinação das propriedades cerâmicas do material, segundo a ASTM (1984). Além dessas análises no agregado produzido fez-se difração de raios-X e microscopia eletrônica de varredura.

\section{RESULTADOS E DISCUSSÕES}

A distribuição granulométrica das pelotas e do carvão vegetal classificados para a realização dos experimentos está apresentada na Figura 2, onde apresentaram diâmetro médio no valor de $5,23 \mathrm{~mm}$ para as pelotas e $2,17 \mathrm{~mm}$ para o carvão vegetal.

Figura 2 - Distribuição granulométrica das pelotas (a) e do carvão vegetal (b). 


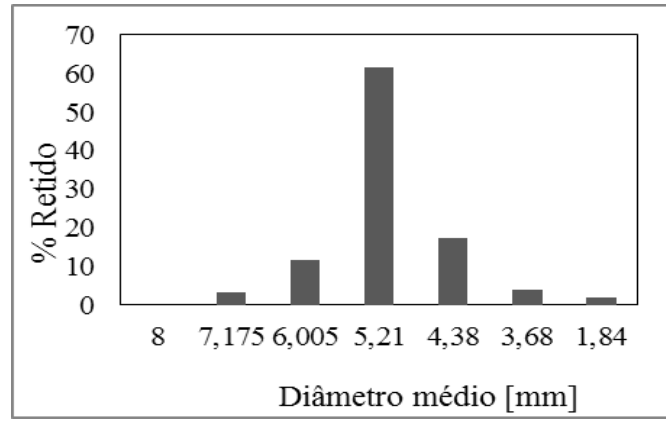

(a)

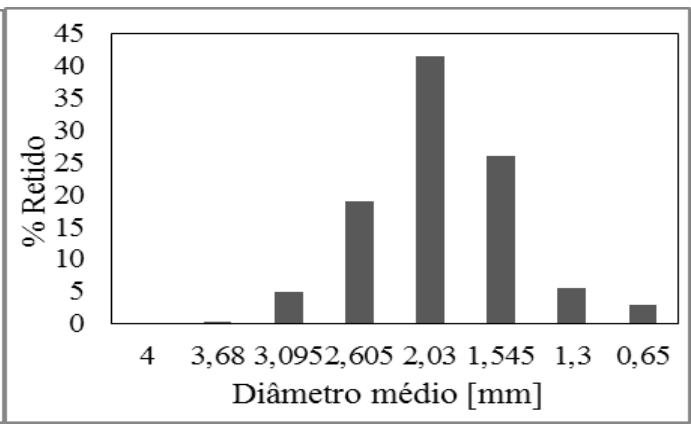

(b)

A Figura 3 apresenta a evolução da temperatura ao longo do reator para os experimentos. As evoluções da temperatura representada nas respectivas Figuras possuem aspectos semelhantes, em que a temperatura em cada termopar atingiu um valor máximo seguido de uma redução gradual, caracterizando o avanço da frente de combustão, onde para o $1^{\circ}$ Experimento o valor máximo de temperatura foi de $1.324,1^{\circ} \mathrm{C}$ e para o $2^{\circ}$ Experimento $1.377,0^{\circ} \mathrm{C}$.

Figura 3 - Evolução da temperatura do $1^{\circ}$ Experimento (a) e $2^{\circ}$ Experimento (b).

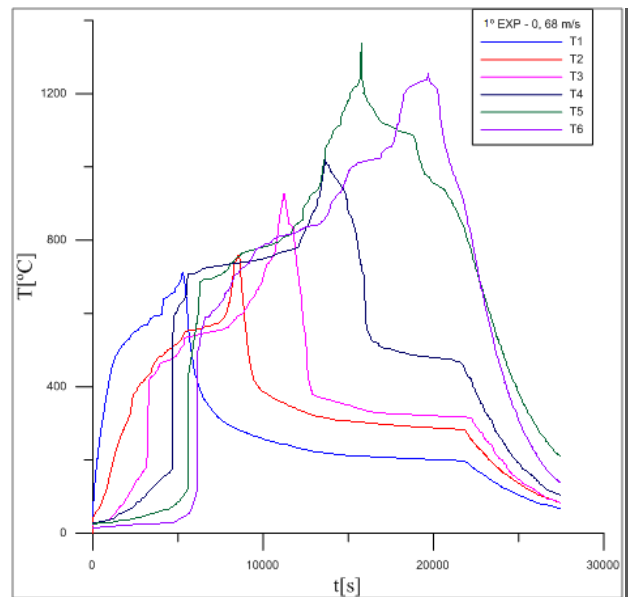

(a)

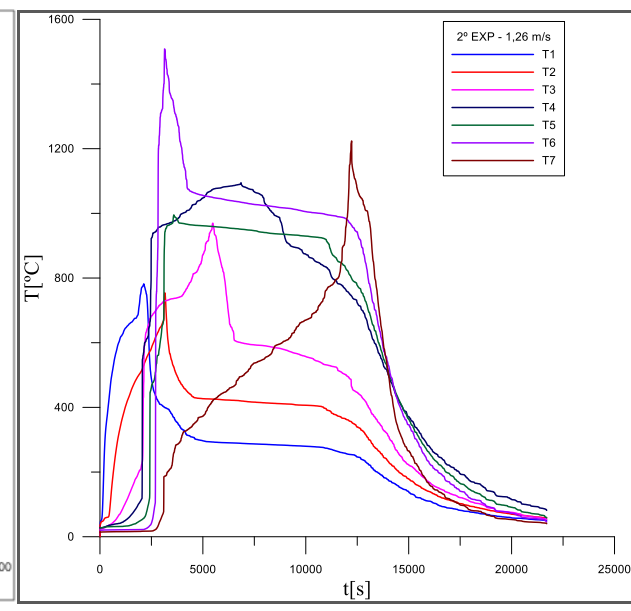

(b)

Os resultados obtidos com a medida das propriedades cerâmicas (porosidade aparente, adsorção de água e massa especifica aparente) do agregado sintético para os experimentos constituem a Tabela 1 .

Tabela 1 - Medida das propriedades cerâmicas dos experimentos

\begin{tabular}{ccc}
\hline Propriedades & $1^{\circ}$ Experimento & $2^{\circ}$ Experimento \\
\hline PA (\%) & 10,03 & 7,90 \\
AA $(\%)$ & 9,91 & 7,62 \\
MEA $\left[\mathrm{g} . \mathrm{cm}^{-3}\right]$ & 0,99 & 1,03 \\
\hline
\end{tabular}

Agregado classificado como leve, apresenta um valor de MEA inferior a $2 \mathrm{~g} . \mathrm{cm}^{-3}$, segundo a ABNT NBR 9935:2011, o qual pode ser evidenciado nos resultados expostos na Tabela 1. 


\section{Congresso Brasileiro de Engenharia Química em Iniciação Científica UFSCar - São Carlos - SP 16 a 19 de Julho de 2017}

Comparando os experimentos observa-se que o $1^{\circ}$ Experimento apresentou menor valor de massa específica aparente em função de sua elevada porosidade, caracterizado pelo fato deste ter sido submetido a um maior tempo de sinterização, média de 8 horas de experimento, comparado às 5 horas para o $2^{\circ}$ Experimento. Os resultados obtidos evidenciam que com o aumento da porosidade aparente tem-se um aumento gradativo da absorção de água e consequente diminuição da massa especifica aparente.

A Microscopia Eletrônica de Varredura (MEV) para uma amostra do agregado produzido no $1^{\circ}$ experimento e no $2^{\circ}$ experimento está representada na Figura 4. Observasse a formação de mulita primária e secundária de morfologia acicular. Tal formação é função das reações de estado sólido que ocorrem em temperaturas superiores a $1.000^{\circ} \mathrm{C}$ e presença, majoritária, de sílico-aluminatos na composição da material-prima.

Figura 4 - Micrografia do agregado produzido no $1^{\circ}$ Experimento (a) e $2^{\circ}$ Experimento (b).

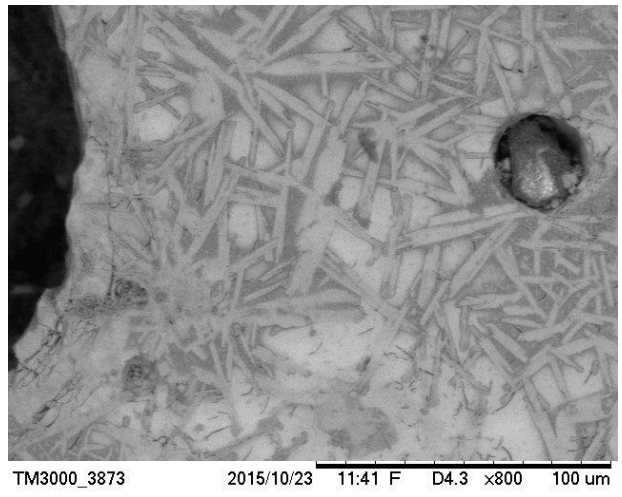

(a)

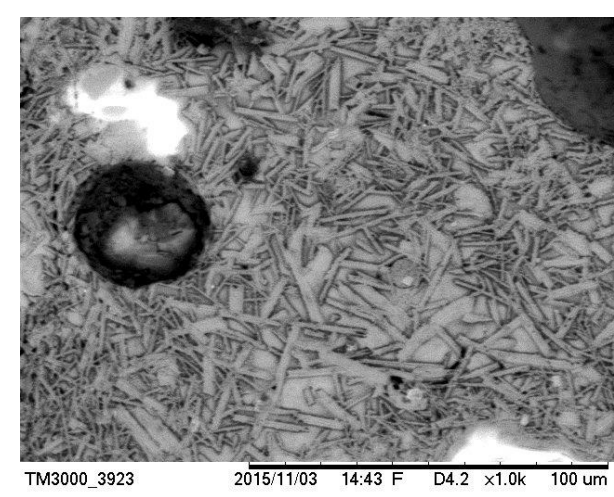

(b)

Os resultados de difração de raios-X (Fig. 5) mostram a presença de quartzo $\left(\mathrm{SiO}_{2}\right)$, mulita $\left(3 \mathrm{Al}_{2} \mathrm{O}_{3} \cdot 2 \mathrm{SiO}_{2}\right)$, anortita $\left(\mathrm{CaAl}_{2} \mathrm{Si}_{2} \mathrm{O}_{8}\right)$ e esseneite $\left(\mathrm{CaFe}^{3+} \mathrm{AlSiO}_{6}\right)$. A formação de quartzo é justificada pela presença de sílica em temperaturas acima de $500^{\circ} \mathrm{C}$ segundo o diagrama de fases. A fase mulita está relacionada a presença de sílico-aluminatos em temperaturas acima de $1000^{\circ} \mathrm{C}$. A constatação das fases anortita e esseneite está vinculada também a presença de sílico aluminatos, além de cálcio e ferro disponível em temperaturas favoráveis, superior a $1000^{\circ} \mathrm{C}$.

Figura 5- Difratogramas referente aos agregados produzidos no $1^{\circ}$ e $2^{\circ}$ Experimento.

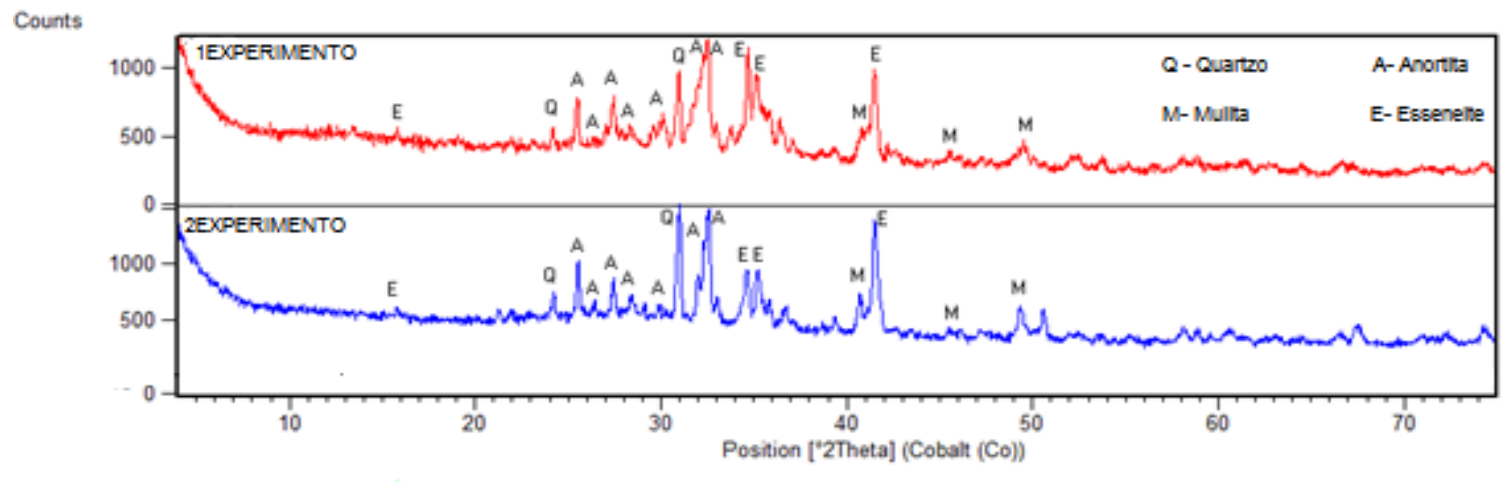




\section{CONCLUSÃO}

Constatou-se a formação de mulita, composto estável responsável pelo aumento de resistência do material, em ambos experimentos. Quando comparados os dois experimentos, constata-se que a variação de velocidade entre estes não interferiu qualitativamente na formação de mulita comprovada nas análises de microscopia eletrônica de varredura e difração de raios-X.

Em conjunto com os dados obtidos para massa específica aparente, os quais classificaram os agregados produzidos como leve, os valores elevados de porosidade e absorção aparente, formam resultados característicos do processo de sinterização de agregado leve.

Desta forma a contribuição desse trabalho é com relação à capacidade que o material produzido tem em substituir agregados naturais, com controle de MEA e resistência mecânica, melhorando a qualidade do concreto e contribuindo para a preservação ambiental.

\section{REFERÊNCIAS}

CABRAL, E. M., SÁ, R. J., VIEIRA, R. K., VASCONCELOS, R. P. Utilização de massas cerâmicas na produção de agregado sintético de argila calcinada para uso em concreto. Cerâmica, v. 54, pp 404-410. 2008.

GOMES NETO, D. P. Dosagem de microconcretos leves de alto desempenho para produção de pré-fabricados de pequena espessura: estudo de caso. 1998. Dissertação (Mestrado) Escola de Engenharia de São Carlos, Universidade de São Paulo, São Carlos, 1998.

MARTINS, M.F.; Structure d'un front de combustion propagé en co-courant dansun lit fixe de schistebitumineuxbroyé, Doctorat de L'Université de Toulouse - L'Institut National Polytechnique de Toulouse - França; 2008.

ROSÁRIO, K. A. do. Concreto com utilização de agregado graúdo sintético produzido a partir da lama vermelha: estudos de dosagem, propriedade e microestrutura. 2013, 113p, il. Dissertação (Mestrado em Engenharia Civil) - Instituto de Tecnologia, Universidade Federal do Pará, Belém-PA, 2013.

SIQUEIRA, J. S. SOUZA, C. A. G., SOUZA, J. A. S. Reaproveitamento de cinzas de carvão mineral na formulação de argamassas. Cerâmica, v.58, pp 275-279. 2012. 